\title{
ACÚMULO DE NUTRIENTES E DECOMPOSIÇÃO DO PALHIÇO DE CANA EM FUNÇÃO DE DOSES DE VINHAÇA
}

\author{
NUTRIENT ACCUMULATION AND DECOMPOSITION OF SUGAR CANE TRASH \\ AS A FUNCTION OF VINASSE DOSES
}

\begin{abstract}
Marcelo ANDREOTTI ; José Eduardo SORIA ${ }^{2}$; Nídia Raquel COSTA ${ }^{3}$; Roberta de Aquino GAMEIRO ${ }^{4}$; Melina Daniel REBONATTI ${ }^{4}$

1. Professor, Doutor, Bolsista de Produtividade CNPq, Departamento de Fitossanidade, Engenharia Rural e Solos, FE, Universidade Estadual Paulista - UNESP, Ilha Solteira, SP, Brasil. dreotti@agr.feis.unesp.br; 2. Mestrando, Programa de Pós-Graduação em Agronomia - Sistemas de Produção, FE - UNESP, Ilha Solteira, SP, Brasil; 3. Doutoranda, Bolsista FAPESP, Programa de PósGraduação em Agronomia - Sistemas de Produção, FE - UNESP, Ilha Solteira, SP, Brasil; 4. Graduandas em Agronomia, FE - UNESP, Ilha Solteira, SP, Brasil.
\end{abstract}

RESUMO: A compreensão sobre a influência da aplicação de vinhaça na decomposição do palhiço e seus efeitos nos atributos químicos do solo e na cultura da cana-de-açúcar é essencial para o bom gerenciamento desse sistema produtivo. Objetivou-se com este estudo avaliar o tempo de decomposição e a ciclagem de nutrientes do palhiço de cana soca ( $3^{\circ}$ ciclo), e seus efeitos sobre os atributos químicos do solo e nas características tecnológicas da cultura, em função de doses de vinhaça. O trabalho foi desenvolvido na região noroeste do estado de São Paulo, sob Argissolo Vermelho Eutrófico, utilizando-se a variedade RB855453. O delineamento experimental utilizado foi o de blocos casualizados com parcelas subdivididas no tempo. Os tratamentos foram constituídos pela aplicação de 4 doses de vinhaça $(0,50,100$ e 200 $\left.\mathrm{m}^{3} \mathrm{ha}^{-1}\right)$. Houve redução de $20,9 \%$ da quantidade de palhiço remanescente durante um ano de avaliação. As doses de vinhaça incrementam a produtividade da cana soca, sem interferir na qualidade da matéria prima. O sistema de cana-crua, em que o palhiço fica depositado sobre o solo e a aplicação de vinhaça, modificam a dinâmica da decomposição do palhiço e alteraram a fertilidade do solo, contribuindo positivamente para a produtividade da cultura.

PALAVRAS-CHAVE: Saccharum spp. Fertirrigação. Ciclagem de nutrientes.

\section{INTRODUÇÃO}

Na colheita mecanizada da cultura da canade-açúcar sem despalha a fogo, as folhas secas são trituradas e os ponteiros cortados são lançados na superfície do solo, formando uma cobertura morta denominada de palhada ou palhiço (OLIVEIRA et al., 1999a). Assim, a quantidade de palhada deixada na superfície do solo varia de acordo com a produtividade total de massa seca (PMS) produzida pela cultura, da variedade cultivada, da idade da planta, da produtividade de colmos e da região de cultivo.

Campos (2003) verificaram valores de produção de palhada próximos a 15\% da PMS total produzida pela cultura da cana-de-açúcar, podendo este valor oscilar entre 13 a $20 \mathrm{t} \mathrm{ha}^{-1} \mathrm{ano}^{-1}$. Neste contexto, a decomposição desses resíduos vegetais promove ainda diversas alterações e benefícios ao sistema produtivo, tais como a melhoria dos atributos físicos, químicos e biológicos do solo (MENDONZA et al., 2002, SIX et al., 2002), auxiliando na mineralização de nutrientes, no incremento da matéria orgânica (MO), na estabilidade dos agregados, influenciando principalmente na produtividade das culturas (BRONICK; LAL, 2005). A presença da palhada pode alterar ainda a dinâmica nutricional da planta, tornando-se importante a realização de pesquisas envolvendo a aplicação de fertilizantes orgânicos ou minerais, corretivos e outros insumos na cultura.

Por se tratar de um processo biológico, a dinâmica da decomposição de resíduos vegetais depende do volume de produção de biomassa, do manejo da cultura de cobertura, da fertilidade e $\mathrm{pH}$ do solo, da qualidade e quantidade dos nutrientes orgânicos disponíveis e de condições climáticas (ALVARENGA et al., 2001), além da qualidade dos resíduos culturais, como a relação $\mathrm{C}: \mathrm{N}$, teores de lignina, celulose, hemicelulose e polifenóis (OLIVEIRA et al., 1999a). Em diversos experimentos, verificou-se correlação entre a manutenção da palhada da cana-de-açúcar e o aumento dos teores de carbono total do solo, com influência de variáveis como tempo de adoção do sistema sem queima, textura do solo e grau de revolvimento do solo na reforma do canavial (CANELLAS et al., 2003). Desta maneira, a compreensão sobre a dinâmica da decomposição dos resíduos vegetais e das taxas de liberação de nutrientes são essenciais para o gerenciamento dessa cultura, tendo em vista os inúmeros benefícios provenientes deste processo, especialmente em solos tropicais, em que as condições edafoclimáticas 
predominantes podem acelerar o processo de decomposição, permanecendo a palhada durante menor período de tempo sobre a superfície do solo.

$\mathrm{O}$ uso da vinhaça como fonte de nutrientes, MO e água, tornou-se excelente opção no manejo da cultura da cana-de-açúcar, pois constitui-se no principal efluente produzido pelas destilarias de etanol (RESENDE et al.,2006b). Desta forma, a fertirrigação com vinhaça é uma técnica bastante difundida nas regiões canavieiras, com resultados satisfatórios em relação às alterações dos atributos químicos do solo ( $\mathrm{MO}, \mathrm{pH}, \mathrm{Ca}, \mathrm{Mg}$ e $\mathrm{K}$ trocáveis) (MEDEIROS et al., 2003).

Segundo Franco et al. (2008), a aplicação de vinhaça na cultura da cana-de-açúcar pode substituir a adubação mineral, tanto para cana-planta quanto para cana-soca, a não ser que o produto seja aplicado em doses excessivas, podendo então diminuir a produtividade e aumentar a salinidade dos solos, proporcionando aumento expressivo nos teores de potássio no solo (CALDEIRA; PACCOLA, 2008). Brito et al. (2009) constataram aumento do teor de $\mathrm{K}$ em diversas classes de solos, variando em profundidade de acordo com as particularidades de cada solo e a dose de vinhaça. Doelsch et al. (2009) descreveram que um dos principais efeitos da vinhaça nos atributos químicos do solo é a elevação temporária do $\mathrm{pH}$, processo que está relacionado com a decomposição da matéria orgânica da vinhaça, que é altamente decomponível. Outros efeitos da vinhaça estão relacionados com o complexo de troca do solo, com o aumento da soma de bases, capacidade de troca de cátions, e aumento nos teores de macro e micronutrientes (CANELLAS et al., 2003).

Desta maneira, a qualidade da matériaprima também pode ser influenciada pela adubação na cultura, seja ela mineral ou orgânica. Além dos benefícios no campo, o correto manejo da adubação torna-se de suma importância na qualidade da canade-açúcar, influenciando a porcentagem aparente de sacarose contida no caldo da cana (POL\%), açúcares redutores (AR), sólidos solúveis (BRIX) e pureza de caldo (SIMÕES NETO et al., 2009; SANTOS et al. 2011; BENETT et al., 2012; TEIXEIRA FILHO et al., 2013). Assim, a qualidade da matéria-prima da cultura é definida como o conjunto de características que a cana-de-açúcar deve apresentar, atendendo às exigências da indústria, por ocasião do processamento, em especial o teor de sacarose e a fibra industrial (MOURA et al., 2005).

Neste contexto, objetivou-se avaliar o tempo de decomposição e a ciclagem de nutrientes do palhiço de cana soca ( $3^{\circ}$ ciclo) e seus efeitos sobre atributos químicos do solo, a produtividade de colmos e nas características tecnológicas da cultura, em função de doses de vinhaça.

\section{MATERIAL E MÉTODOS}

O trabalho foi desenvolvido em área comercial da Usina Vale do Paraná durante a safra de 2008/2009 ( $3^{\circ}$ ciclo, ou seja, $2^{\text {a }}$ soca), localizada no município de Suzanápolis-SP (Latitude 20 $30^{\circ}$ 03" S, Longitude $51^{\circ} 01^{\prime} 30^{\prime}$ W), com altitude predominante de $350 \mathrm{~m}$ e sob Argissolo Vermelho Eutrófico, textura arenosa/média (EMBRAPA, 2006). O tipo climático é Aw, segundo classificação de Köppen, caracterizado como tropical úmido com estação chuvosa no verão e seca no inverno (KÖPPEN; GEIGER, 1928). Na Figura 1 estão apresentados os dados de precipitação pluvial e temperatura média durante o período de realização do experimento. A área experimental estava sendo cultivada com a variedade de cana-de-açúcar RB855453 há dois anos em sistema de colheita mecanizada sem queima, sendo o experimento instalado em agosto de 2008.

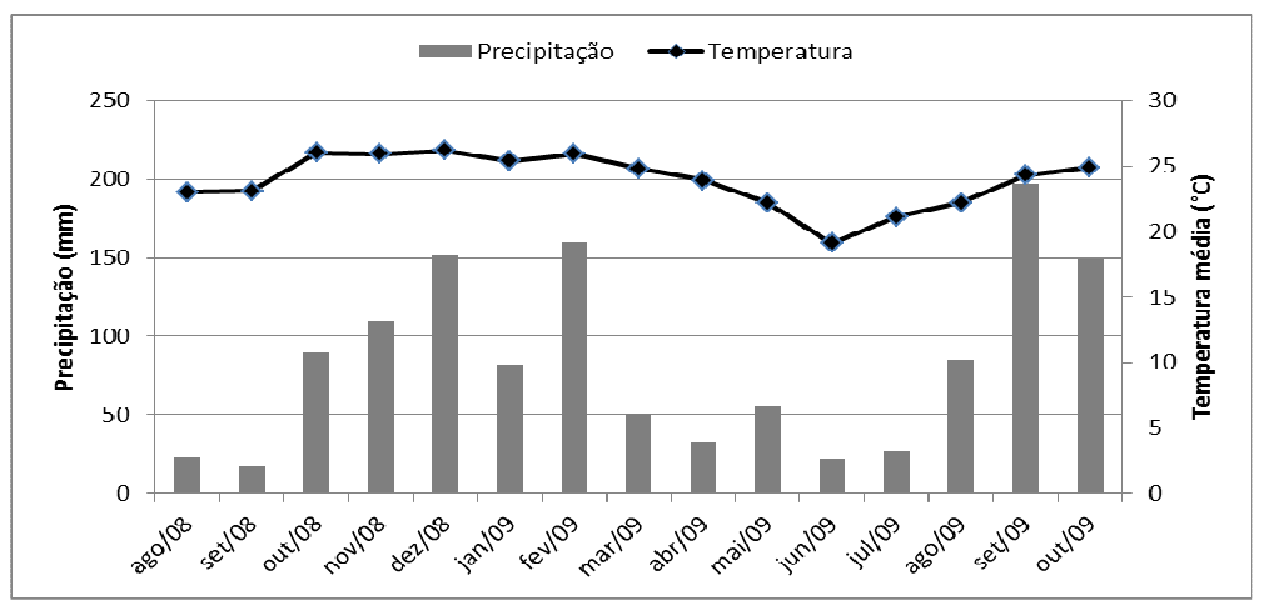

Figura 1. Dados climáticos levantados junto à estação meteorológica situada na Usina Vale do Paraná, no município de Suzanápolis, SP. Período de agosto de 2008 a outubro de 2009. 
O delineamento experimental utilizado foi em blocos casualizados, com quatro repetições em esquema de parcelas subdivididas no tempo. Os tratamentos foram constituídos pela aplicação de 4 doses de vinhaça $\left(0,50,100\right.$ e $\left.200 \mathrm{~m}^{3} \mathrm{ha}^{-1}\right)$ nas parcelas experimentais, quando a cultura da cana soca apresentava 30 dias após o corte (colheita da $1^{\mathrm{a}}$ soca). Nas subparcelas foram realizadas avaliações mensais da decomposição da palhada durante um período de 12 meses (de 30 em 30 dias), após aplicação da vinhaça. Cada unidade experimental foi constituída por 5 linhas de cana, espaçadas em $1,5 \mathrm{~m}$ com $10 \mathrm{~m}$ de comprimento, perfazendo uma área de $75 \mathrm{~m}^{2}$ por parcela. Considerou-se como área útil da parcela, as três linhas centrais, desprezandose um metro em cada extremidade.

Após a rebrota da soqueira, realizaram-se avaliações referentes aos atributos químicos do solo segundo metodologia descrita em Raij et al. (2001). Para tanto, foram determinados os valores de $\mathrm{pH}$ em $\mathrm{CaCl}_{2}$, matéria orgânica (MO), $\mathrm{P}, \mathrm{K}, \mathrm{Ca}, \mathrm{Mg}$ e acidez potencial $(\mathrm{H}+\mathrm{Al})$, e calculados os valores de soma de bases (SB), capacidade de troca catiônica (CTC) e saturação por bases (V\%). Estas avaliações foram realizadas nas camadas de $0-0,20 \mathrm{~m}$ e 0,20 $0,40 \mathrm{~m}$, sendo efetuadas trimestralmente, durante todo o ciclo da cana soca. Sendo assim, as avaliações se deram em cinco épocas distintas: na data de implantação do experimento e aos 90, 180, 270 e 360 dias após aplicação das doses de vinhaça. Em cada parcela experimental a amostragem foi realizada nas referidas profundidades, com o auxílio de um trado de rosca, coletando-se 10 amostras simples nas entrelinhas da cana, por parcela, para a obtenção de uma amostra composta.

Após a colheita mecanizada da cultura realizada na safra de 2008, correspondendo ao $2^{\circ}$ corte $\left(1^{\text {a }}\right.$ soca $)$, determinou-se a quantidade de palhada deixada sobre a superfície do solo. Para tanto, realizou-se a coleta aleatória de cinco amostras de $0,25 \mathrm{~m}^{2}$ de área por unidade experimental, utilizando-se um quadrado de metal $(0,5 \times 0,5 \mathrm{~m})$ para determinação da massa seca residual (palha). Assim, com base na média das amostras de palha sobre a superfície do solo, calculou-se a produtividade de massa seca produzida pela cultura. Em cada uma das amostragens, o material coletado foi pesado e as amostras foram colocadas em estufa de ventilação forçada de ar a $65^{\circ} \mathrm{C}$ até massa constante, para a quantificação da produtividade de massa seca remanescente (MSR), a qual foi extrapolada para $\mathrm{kg}$ $\mathrm{ha}^{-1}$.

Após estas avaliações, acondicionou-se em bolsas de nylon denominadas "litter bags" de 0,16 $\mathrm{m}^{2}(0,40 \mathrm{~m}$ de comprimento por $0,40 \mathrm{~m}$ de largura), quantidade proporcional de palha produzida por cada unidade experimental, conforme avaliação realizada anteriormente, utilizando-se quantidade equivalente ao hectare. As bolsas de nylon foram depositadas em contato direto com a superfície do solo da respectiva parcela e a palha utilizada para o enchimento destas foi a mesma cortada pela colhedora, simulando assim, o tamanho natural dos fragmentos obtidos durante a colheita da cultura.

A cada 30 dias, durante um período de 12 meses (setembro de 2008 a agosto de 2009), uma bolsa foi retirada de cada parcela, a fim de avaliar o remanescente de palha no interior da mesma, para posterior determinação do tempo de decomposição da massa seca. Para tanto, foi coletada a massa fresca de cada bolsa, posteriormente limpa em peneira e determinada a massa seca (estufa a $65^{\circ} \mathrm{C}$ até massa constante).

Após a instalação das bolsas nas respectivas parcelas experimentais, foram aplicadas 4 doses de vinhaça $\left(0 ; 50 ; 100\right.$ e $\left.200 \mathrm{~m}^{3} \mathrm{ha}^{-1}\right)$, com auxílio de um aplicador motorizado com controle de vazão pressurizado, com correção da quantidade a ser aplicada pela vazão e área total de cada parcela (75 $\mathrm{m}^{2}$ ). A vinhaça utilizada foi disponibilizada pela própria usina, sendo esta a única fonte de nutrientes fornecida para a cultura, em que esta apresentava-se com $98,62 \%$ de umidade e densidade de $1,01 \mathrm{Mg} \mathrm{m}^{-}$ 3. Com o intuito de caracterizar a vinhaça, foi realizada uma análise química da mesma, que apresentou os seguintes valores: $262,64 \mathrm{mg}^{-1 e} \mathrm{~N} \mathrm{~L}^{-}$ ${ }^{1} ; 214,95 \mathrm{mg}$ de $\mathrm{P} \mathrm{L}^{-1} ; 133,74 \mathrm{mg}$ de S L ${ }^{-1} ; 127,40$ $\mathrm{mg}$ de $\mathrm{Ca} \mathrm{L}^{-1} ; 20,74 \mathrm{mg}$ de $\mathrm{Mg} \mathrm{L}^{-1} ; 3180 \mathrm{mg} \mathrm{de} \mathrm{K} \mathrm{L}^{-}$ ${ }^{1}$ e $72,20 \mathrm{mg}$ de $\mathrm{Na} \mathrm{L}^{-1}$.

Na data de implantação do experimento, e aos 90, 180 e 360 dias após a implantação, foram determinados os teores de $\mathrm{N}, \mathrm{P}, \mathrm{K}, \mathrm{Ca}, \mathrm{Mg}$ e $\mathrm{S}$ na massa seca da palhada remanescente contida nas bolsas, para avaliação da disponibilização dos nutrientes da palha em função do tempo, utilizandose metodologia descrita por Malavolta et al. (1997). As quantidades dos nutrientes contidos na palhada foram obtidas, tomando-se como base, o total da matéria seca produzida e o teor do nutriente determinado na palhada, extrapolando-se os resultados para $\mathrm{kg} \mathrm{ha}^{-1}$.

$\mathrm{Na}$ colheita da cultura (cana soca), realizada em outubro de 2009, foram colhidas as 3 linhas centrais com $8 \mathrm{~m}$ de comprimento, sendo avaliada a produtividade de colmos $\left(\mathrm{t} \mathrm{ha}^{-1}\right)$ com auxílio de uma balança de campo. No material coletado avaliaramse os seguintes atributos tecnológicos da cana-deaçúcar utilizando-se 10 colmos por parcela: açúcares redutores da cana e do caldo $\left(\mathrm{AR}_{\mathrm{CANA}} \mathrm{e} \mathrm{AR}_{\mathrm{CALDO}}\right)$, 
sacarose polarizável da cana e do caldo $\left(\mathrm{POL}_{\mathrm{CANA}} \mathrm{e}\right.$ POL $_{\text {CALDO }}$ ), sólidos solúveis totais da cana e do

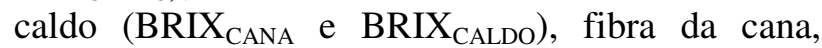
pureza do caldo $\left(\mathrm{PZA}_{\mathrm{CALDO}}\right)$ e açúcares totais recuperáveis (ATR). As análises foram realizadas pelo laboratório da Usina Vale do Paraná S/A, conforme o manual do Conselho dos Produtores de Cana-de-açúcar, Açúcar e Álcool do Estado de São Paulo (CONSECANA, 2003).

Os resultados dos atributos avaliados foram submetidos à análise de variância, aplicando o teste $\mathrm{F}(\mathrm{p} \leq 0,05$ e $\mathrm{p} \leq 0,01)$ e as médias foram ajustadas pela análise de regressão polinomial, com o auxilio do programa SISVAR ${ }^{\circledR}$ (FERREIRA, 2011).

\section{RESULTADOS E DISCUSSÃO}

De maneira geral, verificaram-se elevadas quantidades de nutrientes contidas no palhiço remanescente de cana-de-açúcar em função da aplicação de doses de vinhaça e decomposição no período de 360 dias (Tabela 1). Estes valores são provenientes de apenas um corte da cana soca $\left(2^{\circ}\right.$ ciclo ou $1^{\text {a }}$ soca). Desta maneira, constatou-se que houve ajuste de regressão quadrática para efeito da vinhaça sobre a palha remanescente, com ponto de máximo de $137 \mathrm{~m}^{3} \mathrm{ha}^{-1}$ (Figura 2A). Portanto, podese inferir que a aplicação de doses superiores a esta proporcionaram uma redução da decomposição do palhiço. Isto pode ter ocorrido devido ao efeito de doses elevadas de vinhaça suprirem as necessidades nutricionais da massa microbiana. Assim, ao invés da massa microbiana degradar o palhiço, com relação C:N alta (VITTI et al., 2008), para suprir suas necessidades nutricionais, ela pode ter imobilizado os nutrientes advindos da vinhaça de relação C:N abaixo de 20/1 (CARNEIRO et al., 2004).

Para o efeito de tempo de degradação da palha, houve ajuste logarítmico para a massa seca remanescente sobre o solo (Figura 2B). Crusciol et al. (2005) verificaram que a decomposição dos resíduos vegetais mantidos sobre o solo podem ser ajustados a modelos lineares. Verificou-se que a porcentagem de palhiço remanescente, em relação à porcentagem total depositada sobre a superfície do solo decresceu mais rapidamente no início do período de decomposição (primeiros 90 dias), tornando-se o processo mais lento após este período. Tal constatação pode ser atribuída ao efeito da vinhaça em reduzir a relação $\mathrm{C}: \mathrm{N}$ do palhiço e também aos fatores climáticos durante o período de realização do experimento, ou seja, pela elevada temperatura e precipitação pluvial nos meses de outubro de 2008 a fevereiro de 2009 (Figura 1). Entretanto, estes fatores climáticos apresentaram redução de valores a partir do mês de março, com os menores valores ocorridos em junho de 2009. Desta maneira, de acordo com Oliveira et al. (1999b), a mineralização dos resíduos vegetais é intensamente influenciada pela temperatura e pela umidade do solo e do palhiço, como constatado na presente pesquisa.

Tabela 1. Produtividade de massa seca remanescente (MSR) de palhiço ao final de um período de 360 dias após aplicação das doses de vinhaça e quantidade de nutrientes acumulado no palhiço de cana soca, em função dos dias após a aplicação de vinhaça (DAAV). Suzanápolis, SP (2009).

\begin{tabular}{cccccccc}
\hline \multirow{2}{*}{ Tratamentos } & MSR & $\mathrm{N}$ & $\mathrm{P}$ & $\mathrm{K}$ & $\mathrm{Ca}$ & $\mathrm{Mg}$ & $\mathrm{S}$ \\
\cline { 2 - 8 } Vinhaça $\left.\boldsymbol{( m}^{3}\right)$ & $*$ & $\mathrm{~ns}$ & $*$ & $\mathrm{~ns}$ & $*$ & $\mathrm{~ns}$ & $*$ \\
\hline 0 & 13.714 & 74,4 & 1,8 & 38,8 & 44,0 & 19,6 & 23,4 \\
50 & 14.787 & 90,4 & 2,7 & 48,2 & 48,1 & 21,9 & 27,8 \\
100 & 15.872 & 86,5 & 3,1 & 42,0 & 52,9 & 20,3 & 28,4 \\
200 & 15.403 & 90,6 & 3,6 & 42,7 & 55,4 & 25,1 & 30,2 \\
\hline CV \% & 16,05 & 20,76 & 36,26 & 51,72 & 43,36 & 43,07 & 29,72 \\
\hline $\boldsymbol{D A A} \boldsymbol{V}$ & $*$ & $*$ & $\mathrm{~ns}$ & $\mathrm{~ns}$ & $*$ & $\mathrm{~ns}$ & $*$ \\
\hline 0 & 17.832 & 78,1 & 2,2 & 39,4 & 45,5 & 15,6 & 22,5 \\
90 & 14.953 & 100,6 & 3,0 & 46,3 & 58,7 & 25,5 & 33,5 \\
180 & 15.422 & 91,3 & 3,3 & 48,2 & 53,4 & 26,5 & 31,4 \\
360 & 14.102 & 75,8 & 2,7 & 37,8 & 42,8 & 19,2 & 22,5 \\
\hline CV \% & 23,10 & 26,77 & 53,60 & 36,47 & 24,38 & 27,98 & 22,40 \\
\hline
\end{tabular}

ns, e * são respectivamente, não significativo, significativo a 5\% pelo teste "F"., sem ou com ajuste de regressão polinomial. 
(A) MSR x Vinhaça

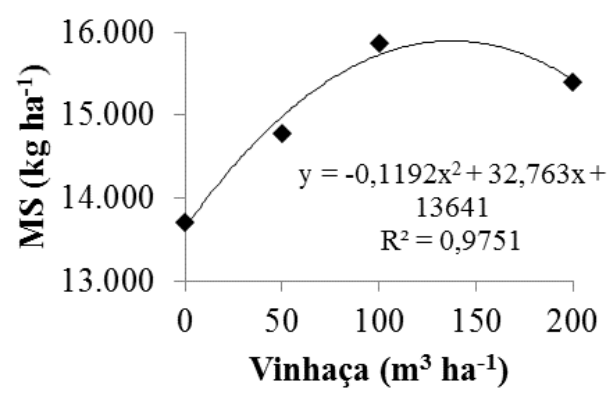

${ }^{(C)}$ N $x$ DAAV

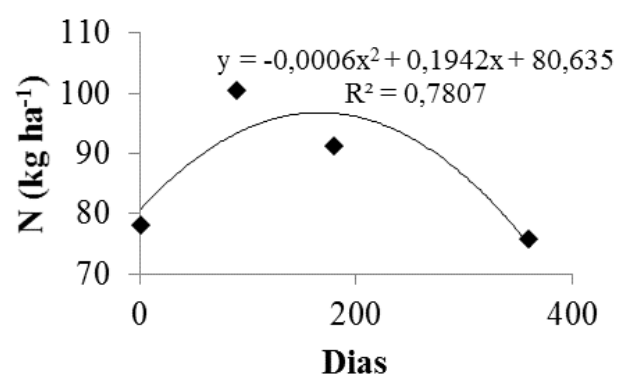

(E) Ca x Vinhaça

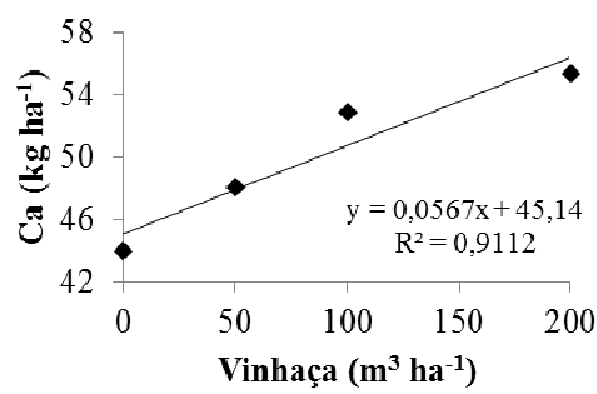

(G) S x Vinhaça

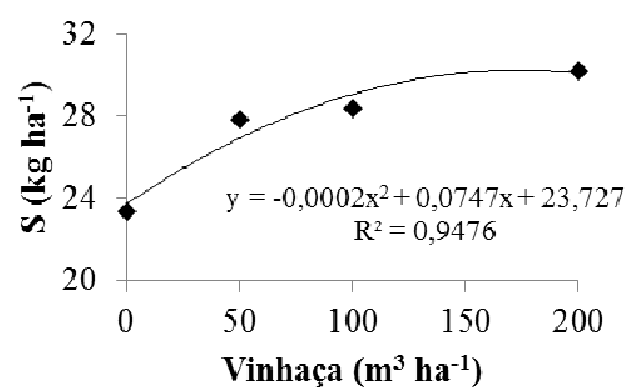

(B) MSR x DAAV
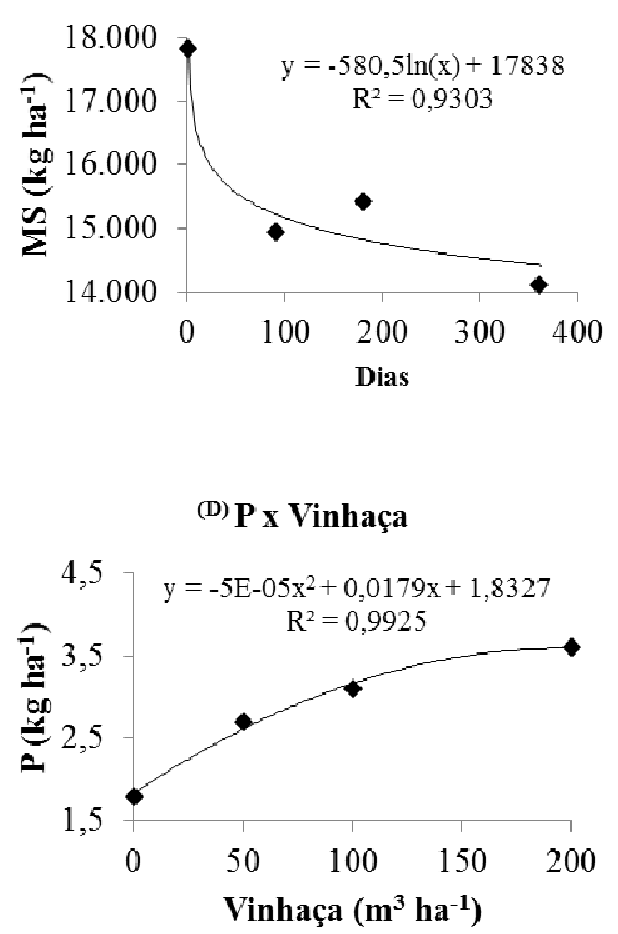

(F) Ca $x$ DAAV

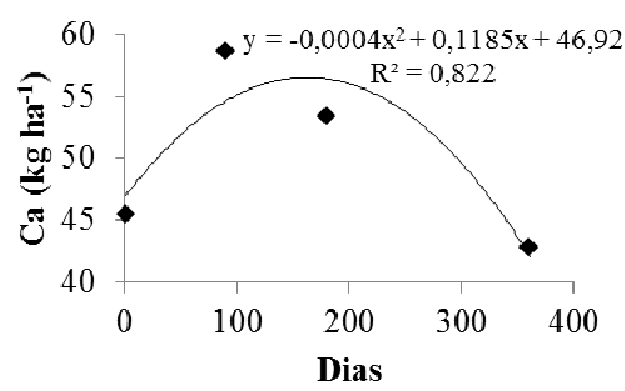

(H) S X DAAV

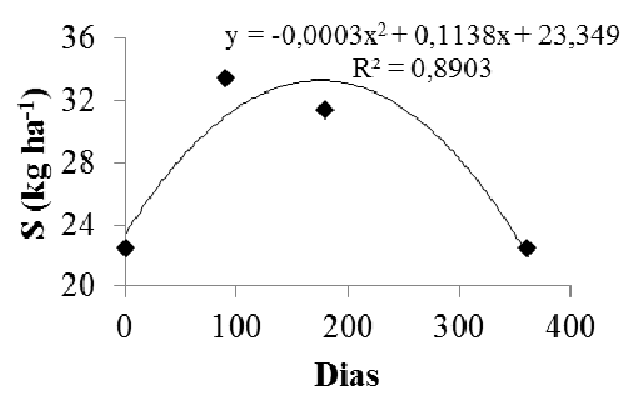

Figura 2. Regressões referentes a produtividade de massa seca residual (MSR) em função de doses de vinhaça (A) e DAAV (B), quantidade de $\mathrm{N}$ em função de DAAV (C), de $\mathrm{P}$ e $\mathrm{Ca}$ em função de doses de vinhaça (D) e (E), de Ca em função de DAAV (F) e de $\mathrm{S}$ em função de doses de vinhaça (G) e $\operatorname{DAAV}(\mathbf{H})$, respectivamente.

Destaca-se que as condições climáticas, com ênfase a temperatura e pluviosidade nas diferentes estações do ano (Figura 1), podem ter influenciado a decomposição da palhada. Neste contexto, os dados obtidos corroboram os resultados verificados por Campos (2003) até os 
180 dias após a aplicação da vinhaça. Cabe ressaltar-se ainda, que a palhada sobre a superfície do solo, pode proteger este contra oscilações na temperatura do solo, proporcionar maior umidade $\mathrm{e}$ principalmente disponibilizar nutrientes durante $\mathrm{o}$ processo de decomposição da palhada, bem como, mineralização da matéria orgânica.

Normalmente, a decomposição do palhiço, acompanhou a produtividade de massa seca total, sendo que quanto mais palha produzida $\left(\mathrm{kg} \mathrm{ha}^{-1}\right)$, maior remanescência aos 360 DAAV (Figuras 2A e B). Assim, a maior quantidade de palha resulta consequentemente em menor contato com a superfície do solo, fato este que proporciona redução no processo de decomposição dos resíduos vegetais, garantindo que a palhada permaneça sobre o solo durante maior período de tempo.

A redução da produtividade de massa seca remanescente (MSR) de palhiço depositada após a colheita da cultura foi de apenas $20,9 \%$ no período de 360 dias de avaliação. Possivelmente, tal fato foi devido a alta relação $\mathrm{C}: \mathrm{N}$ deste material. Este valor se aproxima do obtido por Oliveira et al. (1999b), que verificaram uma redução de aproximadamente $22 \%$ do palhiço, após um ano de permanência no campo. Vitti et al. (2008), avaliando os mesmos parâmetros em solo semelhante no município de Pradópolis, na região de Ribeirão Preto-SP, observaram uma redução de 64 a $75 \%$ da decomposição do palhiço. Oliveira et al. (1999b) observaram variação na redução de massa seca de 22 a $70 \%$ em dois ambientes agrícolas, sendo a maior decomposição influenciada, possivelmente, pelas irrigações.

Cabe ressaltar ainda, os elevados teores de $\mathrm{N}$ e $\mathrm{K}$ que podem ser liberados ao solo pelos resíduos vegetais (Tabela 1), confirmando serem os nutrientes mais absorvidos e acumulados no tecido vegetal da maior parte das gramíneas (PACHECO et al., 2011; PARIZ et al., 2011). No entanto, devese enfatizar a contribuição do $\mathrm{K}$ liberado pelos resíduos vegetais, o qual, de acordo com Santos et al. (2008), possui uma liberação de $80 \%$ para gramíneas e $90 \%$ para leguminosas, tendo assim importante papel na ciclagem desse nutriente no sistema. Adicionalmente, parte do $\mathrm{N}$ e $\mathrm{P}$, é rapidamente liberada no estádio inicial de decomposição dos resíduos vegetais, podendo também ser perdidos por lixiviação (GAMARODRIGUES et al., 2007).

Para a ciclagem de nutrientes, não houve ajuste de regressão para $\mathrm{N}, \mathrm{K}$ e $\mathrm{Mg}$ por efeito da aplicação de vinhaça e para as quantidades de $\mathrm{P}, \mathrm{K}$ e $\mathrm{Mg}$ ao longo do período de avaliação (360 dias) na palhada remanescente sobre o solo (Tabela 1). Por efeito da aplicação de doses de vinhaça houve ajuste linear crescente para as quantidades de $\mathrm{Ca}$ e ajuste quadrático para as quantidades de $\mathrm{P}$ e $\mathrm{S}$ (Figuras 2E, D e G) resultados estes esperados, em função do acréscimo dos nutrientes contidos na vinhaça aplicada também em doses crescentes. Quanto ao efeito do tempo de degradação da palha foram ajustadas equações quadráticas para $\mathrm{N}, \mathrm{Ca}$ e $\mathrm{S}$ (Figuras 2C, $\mathrm{F}$ e $\mathrm{H}$ ), todas com o mesmo comportamento e com ponto de máximo variando de 148 a 190 dias após o corte e deposição da palha sobre o solo, demonstrando assim o período mínimo de adaptação da massa microbiana em degradar palha de alta relação $\mathrm{C}: \mathrm{N}$ (imobilização temporária), e efeito da própria vinhaça em mistura ao palhiço sobre o solo, e que após esse período a liberação foi lenta e gradual.

De acordo com Oliveira et al. (1999b), os resíduos de cana-de-açúcar apresentam uma reduzida mineralização de $\mathrm{N}$ no período de um ano agrícola, disponibilizando no solo pequena quantidade de N. Oliveira et al. (1999a) observaram que $80 \%$ da quantidade inicial de $\mathrm{N}$ permanecia na palhada. Para a liberação de $\mathrm{K}$ do palhiço, apesar de não ter ocorrido diferença significativa, tanto para as doses de vinhaça como para o tempo de decomposição, Oliveira et al. (1999b) constataram liberação de $93 \%$ do $\mathrm{K}$ contido no palhiço, o que não foi verificado neste trabalho (Tabela 1). Além da liberação de K, Oliveira et al. (1999b) observaram diferenças significativas para a liberação de $\mathrm{Ca}$ e $\mathrm{Mg}$, e Oliveira et al. (1999a) verificaram liberação superior a $60 \%$ dos nutrientes $\mathrm{P}, \mathrm{Ca}, \mathrm{Mg}$ e $\mathrm{S}$ do palhiço.

Pela análise da Tabela 2 verifica-se que não houve efeito das doses de vinhaça para o $\mathrm{pH}$ e os teores de $\mathrm{P}, \mathrm{Ca}$ e $\mathrm{H}+\mathrm{Al}$, assim como não houve efeito das épocas de avaliação em função da decomposição do palhiço para $\mathrm{pH}, \mathrm{MO}, \mathrm{H}+\mathrm{Al}$, CTC e V\% na camada de 0 a 0,20 m. Em relação à aplicação de doses de vinhaça houve ajuste de equação linear positiva com o incremento da dose para MO (Figura 3A), fato este justificável pela carga biológica deste resíduo da indústria sucroalcooleira e também pela textura arenosa da camada superficial do Argissolo coberto por palhiço advindo da colheita mecanizada. Em trabalho realizado por Brito et al. (2009), os autores não observaram efeito das doses de vinhaça aplicadas no teor de carbono orgânico do solo. 
Tabela 2. Valores médios dos atributos químicos do solo em função das doses de vinhaças e tempo de decomposição do palhiço em função dos dias após a aplicação de vinhaça (DAAV) para a camada de 0 a 0,20 m. Suzanápolis, SP (2009).

\begin{tabular}{ccccccccccc}
\hline \multirow{2}{*}{ Tratamentos } & $\mathrm{pH}$ & $\mathrm{M} . \mathrm{O}$. & $\mathrm{P}$ & $\mathrm{K}$ & $\mathrm{Ca}$ & $\mathrm{Mg}$ & $\mathrm{H}+\mathrm{Al}$ & $\mathrm{SB}$ & $\mathrm{CTC}$ & $\mathrm{V}$ \\
\cline { 2 - 11 } & $\left(\mathrm{CaCl}_{2}\right)$ & $\mathrm{g} \mathrm{dm}^{-3}$ & $\mathrm{mg} \mathrm{dm}^{-3}$ & & & \multicolumn{2}{c}{$\mathrm{mmol}_{\mathrm{c}} \mathrm{dm}^{-3}$} & & & $\%$ \\
\hline Vinhaça $\left(\boldsymbol{m}^{3}\right)$ & $\mathrm{ns}$ & $*$ & $\mathrm{~ns}$ & $*$ & $\mathrm{~ns}$ & $*$ & $\mathrm{~ns}$ & $*$ & $*$ & $*$ \\
\hline 0 & 4,6 & 18,4 & 4,1 & 1,5 & 14,0 & 4,4 & 27,4 & 19,9 & 47,3 & 42,2 \\
50 & 4,5 & 18,3 & 4,6 & 3,0 & 14,4 & 5,2 & 25,2 & 21,8 & 47,8 & 46,8 \\
100 & 4,7 & 19,7 & 4,2 & 2,8 & 13,6 & 5,3 & 26,8 & 22,6 & 48,6 & 45,1 \\
200 & 4,7 & 20,3 & 4,6 & 3,0 & 15,2 & 5,8 & 25,3 & 24,1 & 49,4 & 48,7 \\
\hline CV \% & 13,5 & 30,5 & 19,2 & 27,2 & 35,6 & 26,7 & 16,3 & 32,5 & 20,0 & 13,5 \\
\hline $\boldsymbol{D A A} \boldsymbol{V}$ & $\mathrm{ns}$ & $\mathrm{ns}$ & $* *$ & $* *$ & $* *$ & $* *$ & $\mathrm{~ns}$ & $* *$ & $\mathrm{~ns}$ & $\mathrm{~ns}$ \\
\hline 0 & 4,7 & 21,2 & 4,9 & 1,4 & 16,2 & 6.4 & 25,6 & 24,1 & 49,7 & 47,9 \\
90 & 4,6 & 18,2 & 4,5 & 2,7 & 15,7 & 5,6 & 27,4 & 24,0 & 51,4 & 46,5 \\
180 & 4,5 & 18,9 & 4,5 & 2,8 & 13,1 & 4,4 & 22,3 & 20,3 & 42,6 & 47,5 \\
270 & 4,7 & 18,2 & 3,9 & 3,0 & 13,1 & 4,4 & 29,8 & 20,9 & 50,7 & 45,3 \\
360 & 4,6 & 19,3 & 4,1 & 3,0 & 13,0 & 4,2 & 25,6 & 21,2 & 46,8 & 45,1 \\
\hline CV \% & 11,6 & 13,6 & 11,9 & 27,2 & 17,4 & 21,5 & 9,4 & 15,2 & 7,6 & 9,2 \\
\hline
\end{tabular}

Em virtude da aplicação da vinhaça constata-se que pela constituição química deste resíduo, o incremento da dose resultou em ajustes quadráticos para os teores de $\mathrm{K}$ e $\mathrm{Mg}$ (Figuras 3C e F) e aumento linear da SB, CTC e consequentemente da V\% (Figuras 4A, C e D). O aumento da CTC pode ser atribuído ao aumento do teor de MO, já que para os solos tropicais, principalmente os arenosos, grande parte da CTC do

Em relação ao $\mathrm{K}$, resultados semelhantes foram observados por Brito et al. (2005), cujos maiores teores de $\mathrm{K}$ trocável em Espodossolo ocorreram na camada superficial $(0-0,15 \mathrm{~m})$ do perfil do solo. Entretanto, Brito et al. (2009) verificaram aumento da concentração de $\mathrm{K}$ no solo, variando em profundidade de acordo com as propriedades do solo. Estes mesmos autores observaram alterações das concentrações de $\mathrm{Ca}$ e $\mathrm{Mg}$ e aumento no valor de $\mathrm{pH}$. Carneiro et al. (2004) verificaram reações de troca entre $\mathrm{H}^{+}$e $\mathrm{Al}^{3+}$, por $\mathrm{Ca}^{2+}, \mathrm{Mg}^{2+}$ e $\mathrm{K}^{+}$, com a aplicação de vinhaça, aumentando assim a saturação por bases do solo. Melchor et al. (2008) verificaram aumento no teor de potássio disponível de $0,43 \mathrm{cmol}_{\mathrm{c}} \mathrm{kg}^{-1}$ em relação a testemunha aos 15 dias após a aplicação de $250 \mathrm{~m}^{3}$ ha ${ }^{-1}$ de vinhaça e de $0,63 \mathrm{cmol}_{\mathrm{c}} \mathrm{kg}^{-1}$ aos 60 dias após a aplicação. Os mesmos autores evidenciaram ainda que a dose de $150 \mathrm{~m}^{3} \mathrm{ha}^{-1}$ promoveu níveis ótimos de potássio para a cultura da cana-de-açúcar. Entretanto, a dose adequada depende do teor de potássio na vinhaça e no solo. Portanto, no presente trabalho, a vinhaça mostrou-se uma boa alternativa como fonte destes nutrientes para melhoria da fertilidade do solo e nutrição da cana soca (Tabela solo é devida à matéria orgânica do solo (MOS) (RAIJ et al., 2001). Apesar da aplicação de vinhaça proporcionar a diminuição do potencial redox, consumindo íons $\mathrm{H}^{+}$e aumentando o $\mathrm{pH}$, não foi verificado aumento deste atributo químico do solo. Estes dados corroboram os obtidos por Magalhães (2010), que também não observou diferença significativa do $\mathrm{pH}$ em relação as doses de vinhaça aplicadas, mas verificou uma tendência de aumento. 2). Canellas et al. (2003) também observaram que a vinhaça alterou as propriedades químicas do solo, proporcionando melhoria na fertilidade e na qualidade da matéria orgânica do solo.

Quanto ao efeito das épocas de avaliação sobre a fertilidade da camada superficial do solo observa-se que quanto ao teor de $\mathrm{P}$ houve ajuste de equação exponencial (Figura 3B), contudo no valor absoluto do teor de $\mathrm{P}$ nas diferentes épocas (em torno de $4,5 \mathrm{mg} \mathrm{dm}^{-3}$ ) pode-se inferir que este sempre esteve classificado como baixo de acordo com Raij et al. (2001). Com relação às bases trocáveis, pela função não estrutural do $\mathrm{K}$ na planta e pela sua mobilidade no solo, ao longo do ano, o palhiço foi a única fonte deste nutriente, com ajuste quadrático (Figura 3D), apresentando pico de liberação aos 295 dias após a implantação do experimento. Já em relação ao Ca e Mg houve ajuste linear decrescente dos teores no solo (Figuras $3 \mathrm{E}$ e G) e consequente redução da SB (Figura 4B), uma vez que estes nutrientes foram os mais representativos no cálculo da SB. Este comportamento do $\mathrm{Ca}$ e $\mathrm{Mg}$ advêm de suas funções estruturais no tecido vegetal e que pela baixa decomposição da palha ao longo do ano $(20,9 \%)$, 
estes ainda poderiam estar fixados a essa palha remanescente de alta relação $\mathrm{C}: \mathrm{N}$, ou provavelmente, podem ter sido lixiviados por ação de complexos orgânicos pela aplicação da vinhaça.

$\mathrm{Na}$ camada de 0,20 a $0,40 \mathrm{~m}$ (Tabela 3 ) com exceção ao teor de $\mathrm{K}$ por efeito das doses de vinhaça e aos teores de $\mathrm{K}$ e $\mathrm{Mg}$ por efeito do tempo de decomposição do palhiço, não houve ajustes de

(A) MO x Vinhaça

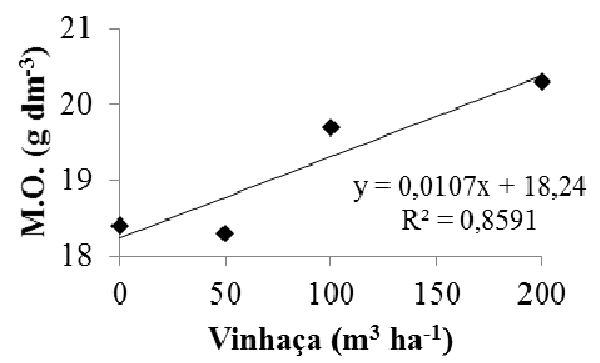

${ }^{(C)} \mathrm{K} \times$ Vinhaça

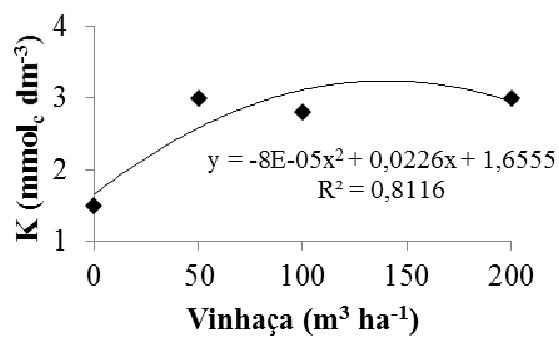

(E) Ca X DAAV

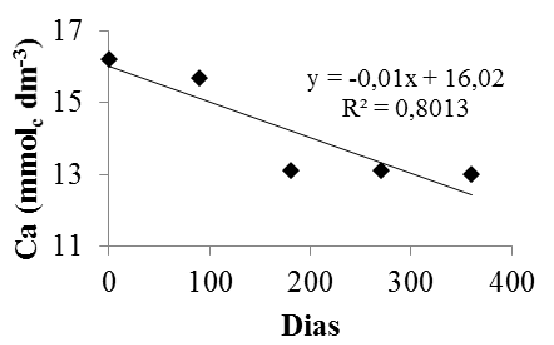

regressões significativas dos tratamentos nos demais atributos químicos do solo. Pode-se verificar que o efeito das doses de vinhaça na camada de 0 a $0,20 \mathrm{~m}$ resultou também em ajuste quadrático do $\mathrm{K}$ em camadas mais profundas (Figura 5A), com pontos de máximo ao redor dos $140 \mathrm{~m}^{3} \mathrm{ha}^{-1}$, confirmando sua alta mobilidade no solo, uma vez que o solo em questão apresenta textura arenosa no horizonte A.

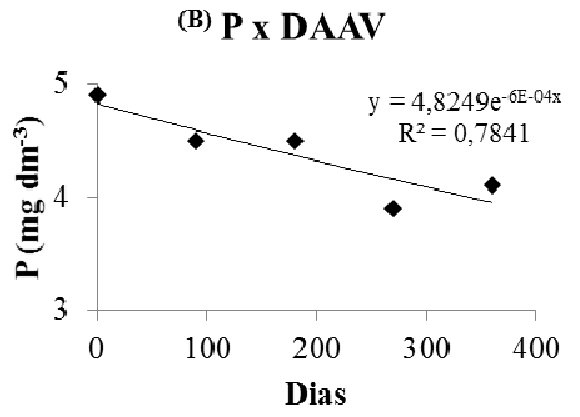

(D) K x DAAV

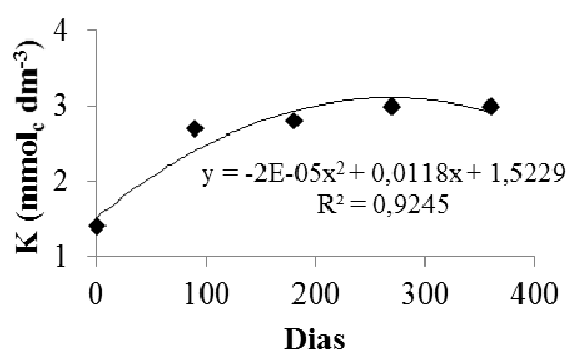

(F) Mg x Vinhaça

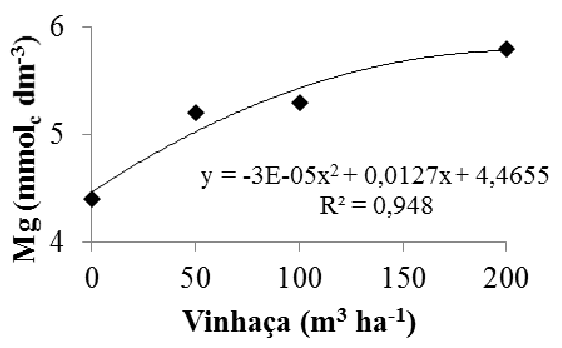

(G) Mg x DAAV

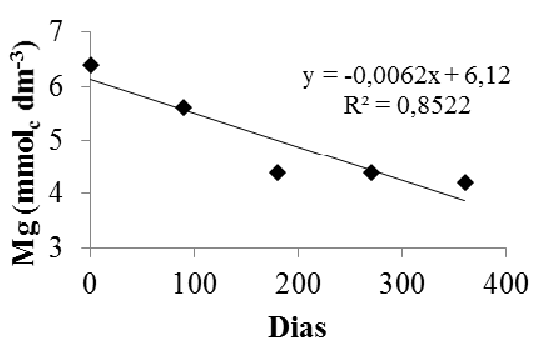

Figura 3. Equações referentes aos teores de $M O$ em função de doses de vinhaça (A), de $P$ em função de DAAV (B), de K em função de doses de vinhaça (C) e DAAV (D), de Ca em função de DAAV (E) e de $\mathrm{Mg}$ em função de doses de vinhaça (F) e DAAV (G), na camada de 0-0,20 m, respectivamente. 
(A) SB x Vinhaça

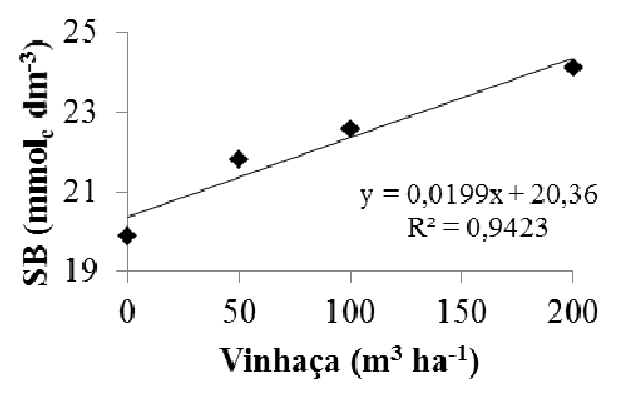

${ }^{(C)}$ CTC x Vinhaça

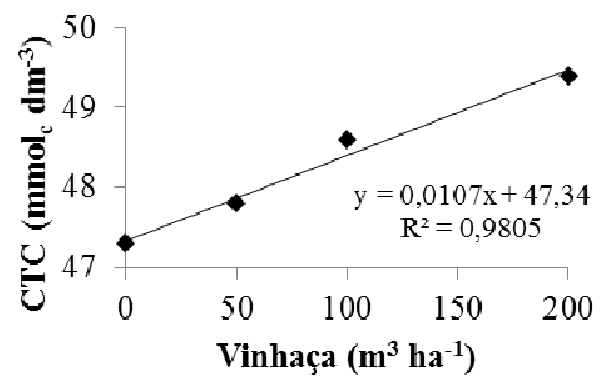

(B) SB x DAAV

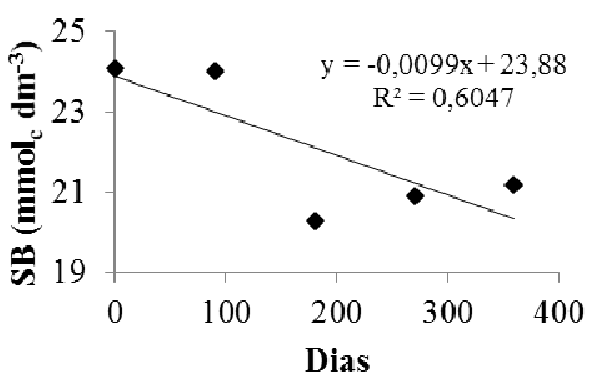

(D) $V \% \times$ Vinhaça

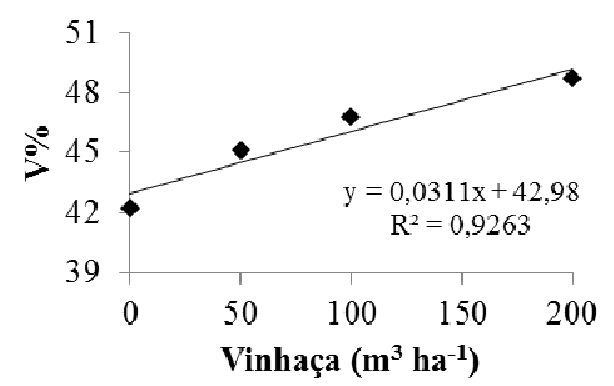

Figura 4. Regressões referentes a SB em função de doses de vinhaça (A) e DAAV (B), da CTC em função de doses de vinhaça (C) e da V\% em função de doses de vinhaça (D), na camada de 0-0,20 m, respectivamente.

Tabela 3. Valores médios dos atributos químicos do solo em função das doses de vinhaças e tempo de decomposição do palhiço em dias após a aplicação de vinhaça (DAAV) para a camada de 0,20 a 0,40 m. Suzanápolis, SP (2009).

\begin{tabular}{|c|c|c|c|c|c|c|c|c|c|c|}
\hline \multirow{2}{*}{ Tratamentos } & $\mathrm{pH}$ & M.O. & $\mathrm{P}$ & $\mathrm{K}$ & $\mathrm{Ca}$ & $\mathrm{Mg}$ & $\mathrm{H}+\mathrm{Al}$ & $\mathrm{SB}$ & CTC & $\mathrm{V}$ \\
\hline & $\left(\mathrm{CaCl}_{2}\right)$ & $\mathrm{g} \mathrm{dm}^{-3}$ & $\mathrm{mg} \mathrm{dm}^{-3}$ & \multicolumn{6}{|c|}{$\mathrm{mmol}_{\mathrm{c}} \mathrm{dm}^{-3}$} & $\%$ \\
\hline $\operatorname{Vinhaça}\left(m^{3}\right)$ & $\mathrm{ns}$ & $\mathrm{ns}$ & $\mathrm{ns}$ & $*$ & $\mathrm{~ns}$ & ns & $\mathrm{ns}$ & $\mathrm{ns}$ & $\mathrm{ns}$ & ns \\
\hline 0 & 4,9 & 15,4 & 3,6 & 0,9 & 15,3 & 5,6 & 21,7 & 21,7 & 43,2 & 50,2 \\
\hline 50 & 4,9 & 16,4 & 4,2 & 1,6 & 16,0 & 6,7 & 24,3 & 24,3 & 46,0 & 52,3 \\
\hline 100 & 4,9 & 14,3 & 3,4 & 1,4 & 14,1 & 6,4 & 21,9 & 21,9 & 43,0 & 50,9 \\
\hline 200 & 4,7 & 14,7 & 3,7 & 1,7 & 14,1 & 6,3 & 22,1 & 22,1 & 44,1 & 50,4 \\
\hline $\mathrm{CV} \%$ & 9,1 & 16,1 & 15,9 & 39,9 & 28,9 & 31,5 & 24,9 & 24,9 & 13,6 & 43,7 \\
\hline$D A A V$ & ns & $\mathrm{ns}$ & ns & $* *$ & ns & $*$ & $\mathrm{~ns}$ & $\mathrm{~ns}$ & $\mathrm{~ns}$ & $\mathrm{~ns}$ \\
\hline 0 & $\overline{5,0}$ & $\overline{15,1}$ & 3,6 & 0,8 & 16,0 & 7,0 & 19,1 & 23,8 & 42,9 & 54,8 \\
\hline 90 & 4,8 & 13,7 & 3,8 & 1,3 & 14,8 & 6,1 & 24,4 & 22,5 & 46,9 & 52,7 \\
\hline 180 & 5,0 & 14,5 & 3,9 & 1,2 & 14,3 & 6,3 & 17,8 & 21,7 & 39,4 & 54,9 \\
\hline 270 & 4,8 & 13,8 & 3,2 & 1,2 & 15,0 & 6,1 & 22,7 & 22,2 & 44,9 & 49,1 \\
\hline 360 & 4,7 & 14,8 & 4,0 & 1,3 & 14,4 & 5,6 & 23,8 & 22,3 & 46,1 & 48,0 \\
\hline $\mathrm{CV} \%$ & 7,4 & 15,9 & 15,1 & 41,7 & 19,8 & 21,3 & 15,0 & 18,1 & 13,2 & 37,1 \\
\hline
\end{tabular}

ns, * e ** são respectivamente, não significativo, significativo a 5 e $1 \%$ pelo teste "F"., sem ou com ajuste de regressão polinomial.

Verificou-se, mesmo nesta camada mais profunda do solo, que o palhiço da cana-de-açúcar foi a principal fonte de potássio, apresentando ajuste quadrático em função do tempo de decomposição
(Figura 5A e B). Este efeito de K pode ser atribuído, em parte, à disponibilização pela decomposição da palha remanescente, ou pela ação das doses de vinhaça. 
${ }^{(A)} \mathrm{K} \times$ Vinhaça

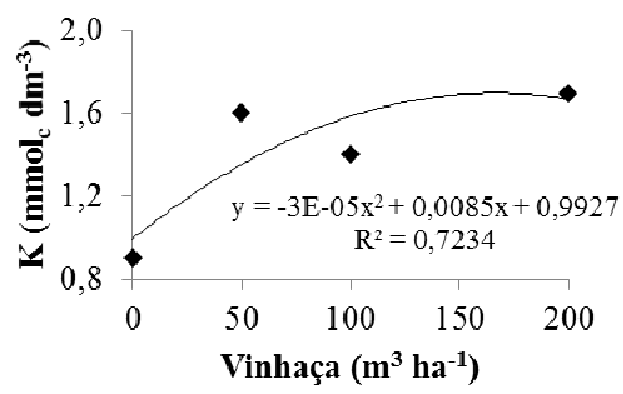

(B) K X DAAV

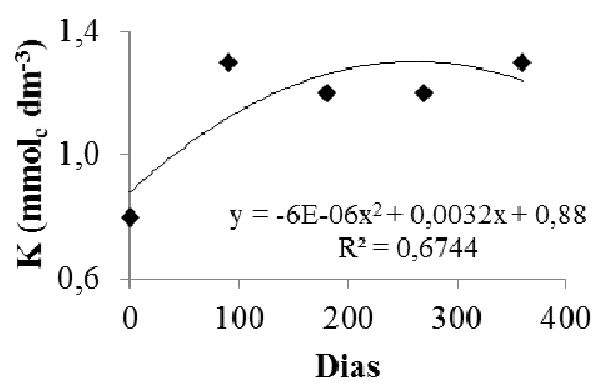

(C) Mg x DAAV

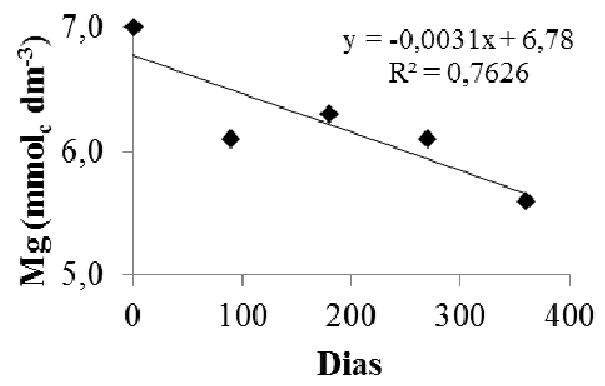

Figura 5. Regressões referentes aos teores de K em função de doses de vinhaça (A) e DAAV (B) e de Mg em função de DAAV (C), na camada de 0-040 m, respectivamente.

$\mathrm{O} \mathrm{K}$ tem função não estrutural na planta, sendo este liberado rapidamente durante o período de decomposição dos resíduos vegetais, e principalmente devido à mobilidade deste nutriente no solo ao longo do ano. Com relação ao teor de $\mathrm{Mg}$ no solo, verificou-se ajuste linear decrescente (Figura 5C), como constatado na camada de 0 a 0,20 m (Tabela 2 e Figura 3G). Tal fato pode ser atribuído à baixa taxa de decomposição da palha ao longo do ano, apresentando valores médios de aproximadamente $20,9 \%$. Assim, pela sua função estrutural, o $\mathrm{Mg}$ pode ter permanecido fixado à palha remanescente, uma vez que esta possui alta relação C:N, o que caracteriza um material mais resistente à degradação. Da mesma maneira, tal efeito pode ter sido ocasionado ainda pela lixiviação proporcionada por ligantes orgânicos da vinhaça, uma vez que o constituinte principal da vinhaça é a matéria orgânica, basicamente sob a forma de ácidos orgânicos.

Para os indicadores de qualidade da canade-açúcar (Tabela 4), os valores de $\mathrm{AR}_{\text {CALDO, }}$ AR $_{\text {CANA }}, \quad$ POL CALDO $_{\text {POL }}$ CANA, BRIX $_{\text {CALDO }}$,

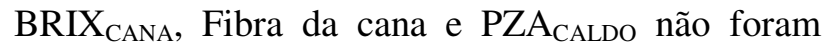
significativos para as doses de vinhaça no presente estudo. Segundo Resende et al. (2006a), a aplicação de vinhaça e a manutenção da palhada no sistema de cana crua não afetam, de forma consistente, as características tecnológicas da cultura de cana-deaçúcar. Carvalho et al. (2013), em trabalho realizado em condições semelhantes ao do presente estudo, não verificaram a influência de doses de gesso e vinhaça na melhoria da qualidade tecnológica da cultura.

Houve ajuste quadrático da produtividade de colmos em relação ao incremento das doses de vinhaça, apresentando produção máxima de $86 \mathrm{t} \mathrm{ha}^{-1}$ na aplicação de aproximadamente $170 \mathrm{~m}^{3} \mathrm{ha}^{-1}$ (Figura 6). Resultados semelhantes foram constatados por Magalhães (2010), que estudando as variedades RB855453 e SP80-1816 submetidas a quatro doses de vinhaça $\left(0,120,240\right.$ e $\left.420 \mathrm{~m}^{3} \mathrm{ha}^{-1}\right)$, constatou que houve aumento de produtividade com o incremento dessas doses, com um comportamento quadrático em relação à produtividade. Este comportamento quadrático também foi observado por Paulino et al. (2002) que aplicaram doses de 0 , $150,300,450$ e $600 \mathrm{~m}^{3} \mathrm{ha}^{-1}$. Segundo Resende et al. (2006a), a aplicação de vinhaça influencia a produção de açúcar e o ganho de produtividade. 
Tabela 4. Teores de sólidos solúveis totais da cana e do caldo (BRIX CANA $_{\text {e BRIX }}$ CALDo), teor de sacarose polarizável da cana e do caldo $\left(\mathrm{POL}_{\mathrm{CANA}}\right.$ e $\mathrm{POL}_{\mathrm{CALDO}}$ ), teor de açúcares redutores da cana e do caldo $\left(\mathrm{AR}_{\mathrm{CANA}} \mathrm{e} \mathrm{AR}_{\mathrm{CALDO}}\right)$, pureza do caldo $\left(\mathrm{PZA}_{\mathrm{CALDO}}\right)$, fibra da cana, açúcares totais recuperáveis (ATR) e produtividade de colmos (PRO) da cana soca ( $3^{\circ}$ corte) em função das doses de vinhaça. Suzanápolis, SP (2009).

\begin{tabular}{|c|c|c|c|c|c|c|c|c|c|c|}
\hline \multirow[t]{2}{*}{ Tratamentos } & $\begin{array}{l}\text { BRIX } \\
\text { CALDO }\end{array}$ & $\begin{array}{c}\text { POL } \\
\text { CALDO }\end{array}$ & $\begin{array}{c}\text { AR } \\
\text { CALDO }\end{array}$ & $\begin{array}{c}\text { PZA } \\
\text { CALDO }\end{array}$ & $\begin{array}{c}\text { BRIX } \\
\text { CANA }\end{array}$ & $\begin{array}{l}\text { POL } \\
\text { CANA }\end{array}$ & $\begin{array}{c}\text { AR } \\
\text { CANA }\end{array}$ & Fibra & ATR & PRO \\
\hline & \multicolumn{8}{|c|}{$\%$} & $\mathrm{~kg} \mathrm{t}$ cana $^{-1}$ & $\mathrm{tha}^{-1}$ \\
\hline $\operatorname{Vinhaça}\left(m^{3}\right)$ & $\overline{\mathrm{ns}}$ & $\overline{\mathrm{ns}}$ & $\overline{\mathrm{ns}}$ & $\overline{\mathrm{ns}}$ & $\overline{\mathrm{ns}}$ & $\overline{\mathrm{ns}}$ & $\overline{\mathrm{ns}}$ & $\overline{\mathrm{ns}}$ & $\overline{\mathrm{ns}}$ & $* *$ \\
\hline 0 & 21,98 & 19,7 & 0,57 & 89,6 & 18,2 & 16,3 & 0,47 & 13,2 & 159,5 & 71,7 \\
\hline 50 & 21,15 & 19,1 & 0,55 & 90,1 & 17,8 & 16,0 & 0,46 & 12,5 & 156,7 & 79,8 \\
\hline 100 & 21,69 & 19,8 & 0,52 & 91,1 & 18,1 & 16,5 & 0,43 & 12,8 & 161,2 & 83,2 \\
\hline 200 & 21,07 & 18,8 & 0,58 & 89,4 & 17,6 & 15,7 & 0,48 & 12,8 & 154,2 & 85,3 \\
\hline CV (\%) & 3,05 & 3,19 & 11,27 & 2,03 & 3,22 & 3,32 & 11,6 & 2,65 & 3,14 & 7,86 \\
\hline
\end{tabular}

ns e ** são respectivamente, não significativo, significativo a $1 \%$ pelo teste "F"., sem ou com ajuste de regressão polinomial.

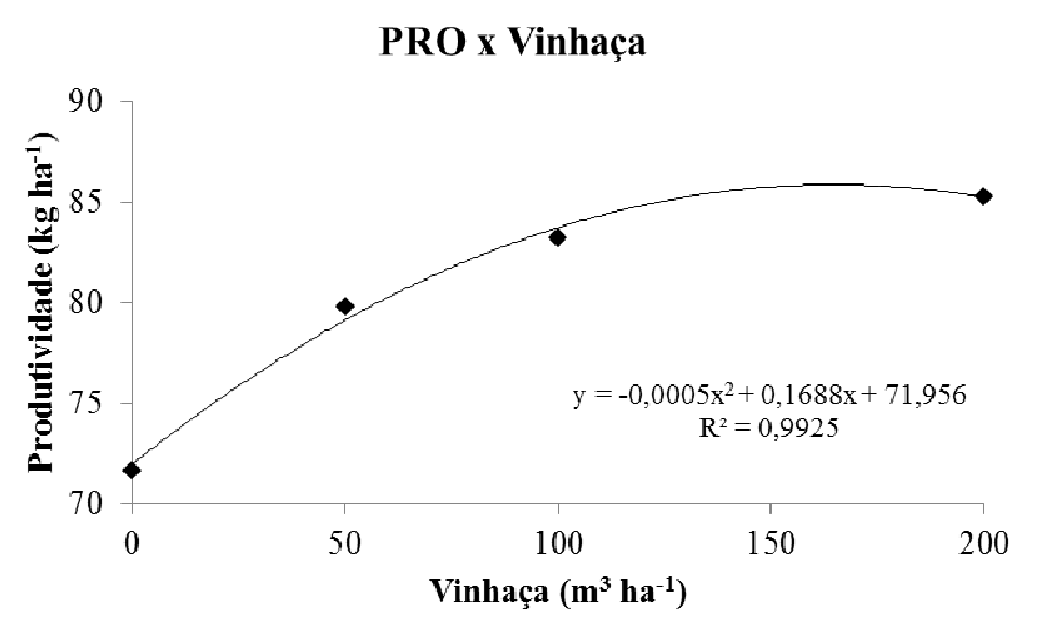

Figura 6. Regressão referente à produtividade de colmos (PRO) da cultura da cana-de-açúcar em função de doses de vinhaça.

\section{CONCLUSÕES}

Houve redução de $20,9 \%$ da quantidade de palhiço remanescente da colheita, após 12 meses da aplicação de vinhaça, com ajuste logarítmico.

As doses de vinhaça e o tempo de decomposição influencia na ciclagem de nutrientes do palhiço, bem como na fertilidade do solo, principalmente na camada de 0 a $20 \mathrm{~m}$.

A aplicação de doses crescentes de vinhaça incrementa a produtividade de colmos de cana até a dose de $170 \mathrm{~m}^{3} \mathrm{ha}^{-1}$, sem interferir na qualidade tecnológica da matéria prima.

ABSTRACT: Understanding the influence of vinasse application on trash decomposition and its effects on soil chemical attributes and sugar cane culture is essential for the good management of the production system. The objective of this study was to assess the time of decomposition and nutrient cycling of the green ratoon cane's trash, and their effects on soil fertility and technological components of crops, in terms of vinasse doses. The study was developed in the northwest region of São Paulo State - Brazil, under Eutrophic Ultisol, using the RB855453 variety. The experimental design was randomized blocks with split plot in time. The treatments were composed of four doses of vinasse $(0,50,100$ and $200 \mathrm{~m}^{3} \mathrm{ha}^{-1}$ ). There was a $20.9 \%$ reduction in the amount of crop residue remaining after one year review. The vinasse doses increased the ratoon cane's yield, without interfering in the raw material quality. The green cane system, in which the trash is deposited on the soil and vinasse application, changes the dynamics of the trash decomposition and modifies the soil fertility, contributing positively to the crop yield.

KEYWORDS: Saccharum spp. Fertigation. Nutrient cycling. 


\section{REFERÊNCIAS}

ALVARENGA, R. C.; LARA CABEZAS, W. A.; CRUZ, J. C.; SANTANA, D. Plantas de cobertura de solo para sistema plantio direto. Informação Agropecuária, v. 22, p. 25-36, 2001.

BENETT, C. G. S.; BUZETTI, S.; SILVA, K. S.; TEIXEIRA FILHO, M. C. M.; PARIZ, C. M.; MAEDA, A. S.; GARCIA, C. M. P. Qualidade e produtividade da cana planta e cana soca em função de doses e fontes de manganês. Bioscience Journal, Uberlândia, v. 28, n. 2, p. 198-205, 2012.

BRITO, F. L.; ROLIM, M. M.; PEDROSA, E. M. R. Efeito da aplicação de vinhaça nas características químicas de solos da zona da mata de Pernambuco. Revista Brasileira de Ciências Agrárias, Pernambuco, v. 4, n. 4, p. 456-462, 2009. http://dx.doi.org/10.5039/agraria.v4i4a14

BRITO, F. L.; ROLIM, M. M.; PEDROSA, E. M. R. Teores de potássio e sódio no lixiviado e em solos após a aplicação de vinhaça. Revista Brasileira de Engenharia Agrícola e Ambiental, Campina Grande, v. 9 (Suplemento), p. 52-56, 2005.

BRONICK, C. J.; LAL, R. Soil structure and management: a review. Geoderma. Amsterdam. v. 124, n. 1/2, p. 3-22, 2005. http://dx.doi.org/10.1016/j.geoderma.2004.03.005

CALDEIRA, D. S. A; PACCOLA, A. A. Influência do manejo da palhada a fertilidade de um cultivo com cana-de-açúcar (Saccharum spp). Revista Energia na Agricultura, Botucatu, v. 23, n. 1, p. 18-31, 2008.

CAMPOS, D. C. Potencialidade do sistema de colheita sem queima da cana-de-açúcar para o sequestro de carbono. 2003. 103p. Tese (Doutorado em Agronomia) - Curso de Pós-Graduação em Agronomia - Área de concentração: Microbiologia Agrícola. Escola Superior de Agricultura "Luiz de Queiroz", Universidade de São Paulo, Piracicaba, 2003.

CANELLAS, L. P.; VELLOSO, A. C. X.; MARCIANO, C. R.; RAMALHO, J. F. G. P.; RUMJANEK, V. M.; REZENDE, C. E.; SANTOS, G. A. Propriedades químicas de um Cambissolo cultivado com cana-de-açúcar, com preservação do palhiço e adição de vinhaça por longo tempo. Revista Brasileira de Ciência do Solo, Viçosa, v. 27, n. 5, p. 935-944, 2003.

CARNEIRO, C. E. A.; FIORETTO, R. A.; FONSECA, I. C. B.; NEVES, C. S. V. J.; CASTRO, A. J. S. Alterações químicas no solo induzidas pela aplicação superficial de palha de cana-de-açúcar, calcário e vinhaça. Semina, Londrina, v. 25, n. 4, p. 265-272, 2004.

CARVALHO, J. M. C.; ANDREOTTI, M.; BUZETTI, S.; CARVALHO, M. P. Produtividade de cana soca sem queima em função do uso de gesso e vinhaça. Pesquisa Agropecuária Tropical, Goiânia, v. 43, n. 1, p. 19, 2013. http://dx.doi.org/10.1590/S1983-40632013000100001

CONSELHO DOS PRODUTORES DE CANA-DE-AÇÚCAR, AÇÚCAR E ÁLCOOL DO ESTADO DE SÃO PAULO- CONSECANA. Manual de Instruções. Piracicaba: CONSECANA, 2003, 92p.

CRUSCIOL, A. C.; COTTICA, R. L.; LIMA, E. V.; ANDREOTTI, M.; MORO, E. \& MARCON, E. Persistência de palhada e liberação de nutrientes do nabo forrageiro no plantio direto. Pesquisa Agropecuária Brasileira, Brasília, v. 40, n. 2, p. 161-168, 2005. http://dx.doi.org/10.1590/S0100-204X2005000200009

DOELSCH, R.; MASION, A.; CAZEVIELLE, P.; CONDOM, N. Spectroscopic characterization of organic matter of a soil and vinasse mixture during aerobic or anaerobic incubation. Waste Management, Oxford, v. 29, n. 6, p. 1929-1935, 2009. http://dx.doi.org/10.1016/j.wasman.2008.12.009

EMBRAPA. Centro Nacional e Pesquisa em Solos. Sistema Brasileiro de Classificação de Solos. Brasilia: Embrapa-SPI; Rio de Janeiro: Embrapa-Solos, 2006. 306 p. 
FERREIRA, D. F. Sisvar: a computer statistical analysis system. Ciência e Agrotecnologia, Lavras, v. 35, n. 6 , p. 1039-1042, 2011.

FRANCO, A.; MARQUES, M. O.; MELO, W. J. de. Sugarcane grown in an oxisol amended with sewage sludge and vinasse: Nitrogen contents in soil and plant. Scientia Agrícola, Piracicaba, v. 65, n. 4, p. 408-414, 2008.

GAMA-RODRIGUES, A. C.; GAMA-RODRIGUES, E. F. \& BRITO, E. C. Decomposição e liberação de nutrientes de resíduos culturais de plantas de cobertura em Argissolo Vermelho-Amarelo na região Noroeste Fluminense (RJ). Revista Brasileira de Ciência do Solo, Viçosa, v. 31, n. 6, p. 1421-1428, 2007.

KÖPPEN, W.; GEIGER, R. Klimate der Erde. Gotha: Verlag Justus Perthes. 1928. Wall-map 150cmx200cm.

MAGALHÃES, V. R. Influência de doses de vinhaça nas características agronômicas de variedades de cana-de-açúcar, cana-planta e atributos químicos do solo. 2010. 89f. Dissertação (Mestrado em Produção Vegetal) - Curso de Pós-Graduação em Produção Vegetal no Semiárido, Universidade de Montes Claros, Montes Claros, 2010.

MALAVOLTA, E.; VITTI, G. C.; OLIVEIRA, S. A. Avaliação do estado nutricional das plantas: Princípios e aplicações. Piracicaba: Potafos, 1997. 319p.

MEDEIROS, S. C. L.; RIBEIRO, S. R.; CONEGLIAN, C. M. R.; BARROS, R. M.; BRITO, N. N.; DRAGONI, G.; TONSO, S.; PELEGRINI, R. Impactos da agroindústria canavieira sobre o meio ambiente. In: Fórum de Estudos Contábeis, 3, 2003, Rio Claro, Anais... Rio Claro: UNICAMP, 2003. CD Rom.

MELCHOR, G. I. H.; GARCIA, S. S.; LÓPEZ, D. J. P.; ESPINOZA, L. C.; ESTRADA, M. C.; ROSADO, O. R. Vinaza y composta de cachaza como fuente de nutrientes em caña de azúcar em um Gleysol Mólixo de Chiapus. Interciência, Caracas, v. 33, n. 2, p. 855-860, 2008.

MENDONZA, H. N. S.; LIMA, E.; ANJOS, L. H. C.; SILVA, L. A.; CEDDIA, M. B.; ANTUNES, M. V. M. Propriedades químicas e biológicas de solo de tabuleiro cultivado com cana-de-açúcar com e sem queima da palhada. Revista Brasileira de Ciência de Solo, Viçosa, v. 24, p. 201-207, 2002.

MOURA, M. V. P. F.; FARIAS, C. H. A.; AZEVEDO, C. A. V.; DANTAS NETO, J.; AZEVEDO, H. M.; PORDEUS, R. V. Doses de adubação nitrogenada e potássica em cobertura na cultura da cana-de-açúcar, primeira soca, com e sem irrigação. Ciência e Agrotecnologia, Lavras, v. 29, p. 753-760, 2005.

OLIVEIRA, M. W.; TRIVELIN, P. C. O.; GAVA, G. J. C., PENATTI, C. P. Degradação da palhada de canade-açúcar. Scientia Agricola, Piracicaba, v. 56, n. 4, p. 803-809, 1999a.

OLIVEIRA, M. W.; TRIVELIN, P. C. O.; PENATTI, C. P.; PICCOLO, M.C. Decomposição e liberação de nutrientes da palhada de cana-de-açúcar em campo. Pesquisa Agropecuária Brasileira, Brasília, v. 34, n. 12, p. 2359-2362, 1999b. http://dx.doi.org/10.1590/S0100-204X1999001200024

PACHECO, L. P.; BARBOSA, J. M.; LEANDRO, W. M.; MACHADO, P. L. O. A.; ASSIS, R. L.; MADARI, B. E. \& PETTER, F. A. Produção e ciclagem de nutrientes por plantas de cobertura nas culturas de arroz de terras altas e de soja. Revista Brasileira de Ciência do Solo, Viçosa, v. 35, n. 5, p. 1787-1799, 2011.

PARIZ, C. M.; ANDREOTTI, M.; BUZETTI, S.; BERGAMASCHINE, F. A.; ULIAN, N. A.; FURLAN, L. C.; MEIRELLES, P. R. L. \& CAVASANO, F. A. Straw decomposition of nitrogen-fertilized grasses intercropped with irrigated maize in integrated crop livestock system. Revista Brasileira de Ciência do Solo, Viçosa, v. 35, n. 6, p. 2029-2037, 2011.

PAULINO, A. F.; MEDINA, C. C.; ROBAINA, C. R. P.; LAURANI, R. A. Produções agrícola e industrial de cana-de-açúcar submetida a doses de vinhaça. Semina, Londrina, v. 23, n. 2, p. 145-150, 2002. 
RAIJ, B. van; ANDRADE, J. C.; CANTARELLA, H.; QUAGGIO, J. A. Análise química para avaliação da fertilidade de solos tropicais. Campinas: Instituto Agronômico, 2001, 285p.

RESENDE, A. S.; SANTOS, A.; XAVIER, R. P.; COELHO, C. H.; GONDIM, A.; OLIVEIRA, O. C.; ALVES, B. J. R.; BODDEY, R. M.; URQUIAGA, S. Efeito da queima da palhada da cana-de-açúcar e de aplicações de vinhaça e adubo nitrogenado em características tecnológicas da cultura. Revista Brasileira de Ciência do Solo, Viçosa, v. 30, n. 6, p. 937-941, 2006a.

RESENDE, A. S.; XAVIER, R. P.; OLIVEIRA, O. C.; URQUIAGA, S.; ALVES, B. J. R., BODDEY, R. M. Long-term effects of pre-harvest burning and nitrogen and vinasse applications on yield of sugar cane and soil carbon and nitrogen stocks on a plantation in Pernambuco, N.E. Brazil. Plant and Soil, v. 281, p. 339-351, 2006b. http://dx.doi.org/10.1007/s11104-005-4640-y

SANTOS, D. H.; SILVA, M. A.; TIRITAN, C. S.; FOLONI, J. S. S.; ECHER, F. R. Qualidade tecnológica da cana-de-açúcar sob adubação com torta de filtro enriquecida com fosfato solúvel. Revista Brasileira de Engenharia Agrícola e Ambiental, Campina Grande, v. 15, n. 5, p. 443-449, 2011.

SANTOS, F. C.; NEVES, J. C. L.; NOVAIS, R. F.; ALVAREZ V., V. H. \& SEDIYAMA, C. S. Modelagem da recomendação de corretivos e fertilizantes para a cultura da soja. Revista Brasileira de Ciência do Solo, Viçosa, v. 32, p. 661-1674, 2008.

SIMÕES NETO, D. E.; OLIVEIRA, A. C.; FREIRE, F. J.; FREIRE, M. B. G. S.; NASCIMENTO, C. W. A.; ROCHA, A. T. Extração de fósforo em solos cultivados com cana-de-açúcar e suas relações com a capacidade tampão. Revista Brasileira de Engenharia Agrícola e Ambiental, Campina Grande, v. 13, n. 4, p. 840-848, 2009.

SIX, J.; FELLER, C.; DENEF, K.; OGLE, S. M.; SA, J. C. M.; ALBRECHT, A. Soil organic matter, biota and aggregation in temperate and tropical soils - effects of no-tillage. Science, Washington, v. 22, p. 755-775, 2002.

TEIXEIRA FILHO, M. C. M.; BUZETTI, S.; GARCIA, C. M. P.; BENETT, C. G. S.; RODRIGUES, M. A. C.; MAESTRELO, P. R.; CELESTRINO, T. S.; GAZOLA, R. N. Qualidade tecnológica e produtividade agroindustrial de cana-de-açúcar submetida a adubação com zinco. Semina: Ciências Agrárias, Londrina, v. 34, n. 4, p. 1603-1614, 2013.

VITTI, A. C.; TRIVELIN, P. C. O; CANTARELLA, H.; FRANCO, C. J.; FARONI, C. E.; OTTO, R.; TRIVELIN, M. O.; TOVAJAR, J. G. Mineralização da palhada e crescimento de raízes de cana-de-açúcar relacionados a adubação nitrogenada de plantio. Revista Brasileira de Ciência de Solo, Viçosa, v. 32, p. 2757 $2762,2008$. 